\title{
Editorial
}

\section{Cystic fibrosis: future trends in care}

In 1983 the British Paediatric Association set up a small working party to look into the way in which cystic fibrosis care in the United Kingdom had developed. This was partly in response to suggestions that the survival of UK patients with cystic fibrosis was inferior to that of patients in Australia and partly because some authorities were promoting the need for special centres for cystic fibrosis care. The data collected provide a useful base for planning cystic fibrosis services and, taken together with recent advances in the genetics and pathophysiology of the disease, allow us to make some prediction for future clinical needs and developments.

\section{EPIDEMIOLOGY}

The numbers of children and adults with cystic fibrosis in the United Kingdom from 1977 to 1985 are shown in the figure. The annual incidence of new cases was relatively constant at 300 over this period and this represents a frequency of $1: 2500$ live births. This number of new cases is likely to remain stable for some years to come, although eventually the numbers may fall if population screening for the carrier state becomes practicable (see below). On the other side of the equation, mortality is now low in childhood and $80 \%$ of children with cystic fibrosis can expect to reach adult life. Life expectancy is also increasing among adults with the disease. The consequences of this are that the numbers of children with cystic fibrosis will remain relatively constant and may eventually decline while the numbers of adults will inexorably increase for at least the next 15-20 years. This is represented in the figure, which extrapolates the British Paediatric Association's survey data to the end of the century. The predictions are probably quite accurate over this period but thereafter become less certain because of the possible reduction of new cases owing to population screening on the one hand and the possible improvements in prognosis with new treatments on the other.

\section{GENETICS AND SCREENING}

In 1985, after many years of searching, the cystic fibrosis gene was localised to the long arm of

Address for reprint requests: Dr DM Geddes, Brompton Hospital, London SW3 8HP. chromosome 7. ${ }^{\prime}$ Since then the hunt has continued and site of the gene has been narrowed down to within 30000 base pairs, although the gene itself has not yet been identified. The practical consequences of these advances can largely be predicted and concern prenatal diagnosis, population screening, and characterisation of the defective protein. Prenatal diagnosis can now be offered to pregnant women known to be at risk of having a child with cystic fibrosis (that is, families with a previous affected child) with greater than $95 \%$ accuracy. The technique consists of chorionic villous sampling followed by comparison of the fetal DNA with that of other family members. Some DNA marker sequences are so close to the cystic fibrosis gene that they are reliably inherited with it within a family and can be used to track the abnormal gene. Accurate prenatal diagnosis is a considerable benefit to families with a child with cystic fibrosis but will make very little difference to the overall incidence of

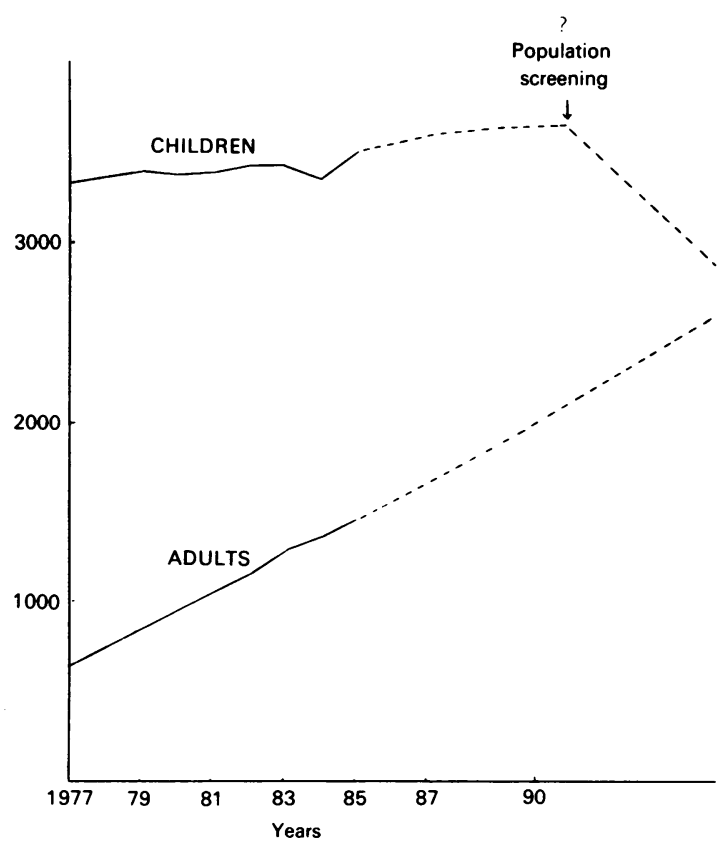

Trends in numbers of children and adults with cystic fibrosis, based on data from the British Paediatric Association survey. 
the disorder as most children with the disease are born in families with no history of it. To identify all women with at risk pregnancies and offer them chorionic villous sampling a carrier detection test is needed. At present carriers can be identified only in families with an affected member by gene probe analysis as described above. Advances in genetic research, however-for example, the development of an oligonucleotide probe that detects the abnormal gene itself - are likely soon to allow carriers to be identified even when there is no family history of cystic fibrosis. When this happens antenatal clinics will be able to offer such screening tests, which would allow most at risk pregnancies to be identified. In theory this approach could lead to the prenatal diagnosis of most babies with cystic fibrosis and the virtual abolition of the disease. The realisation of this dream may be delayed by problems in developing an effective test, the cost of such a test, and the attitude of the general population. A programme of public education may be needed before couples agree to carrier detection testing and possible chorionic biopsy for a condition they have never heard of. Furthermore, as the prognosis of cystic fibrosis improves and a normal lifespan is approached the need to terminate cystic fibrosis pregnancies will be questioned.

\section{PATHOPHYSIOLOGY AND TREATMENT}

An interesting race is developing between the geneticists on the one hand, who are hoping to identify and localise the defective protein by working out the DNA sequence, and the physiologists on the other, who are hoping to define the functional defect and the protein first. The defect has been narrowed down to the control of chloride channel function at the luminal surface of epithelial cells lining the airways and the sweat and pancreatic ducts. ${ }^{23}$ The channel itself appears normal and so some protein, probably associated with the channel, that should encourage it to open but fails to do so is the likely culprit. There is a little evidence that the defect could be bypassed by changing intracellular control mechanisms-for example, free calcium - and this raises the possibility of drug treatment to open the chloride channel. ${ }^{4}$

A second approach is concerned with modifying sodium transport across the same epithelial cells. The argument here is that sodium transport is increased in cystic fibrosis, probably as a result of the chloride channel abnormality, and that excess sodium removal from the lumen pulls water with it and so dries out respiratory secretions. Drugs that reduce sodium transport, such as amiloride, may therefore keep the airways wet and so discourage bacterial colonisation while assisting mucociliary clearance. ${ }^{5}$

Although there is still much to learn about these processes and no direct evidence that any drug which affects ion transport has a role in cystic fibrosis, the chances that a new treatment will be developed in the next 10 years are good. In addition, lung transplant tion has been successful in cystic fibrosis at least in the short term, and is being enthusiastically assessecos When these two trends are set against a background of continuing improvement in prognosis from conven tional management, future prospects for cystic fibrosis are looking highly encouraging.

\section{PATTERNS OF CARE}

For some time those concerned with specialist cystic fibrosis units have been promoting such centres as the best way of providing multidisciplinary care. A sub stantial body of evidence to support the role of cystic fibrosis centres has been published ${ }^{7-9}$ and, althoug this evidence may be criticised on several metk odological grounds, it is the best we have. The recent? British Paediatric Association survey also showed survival advantage for children attending units with more than 40 patients suffering from cystic fibrosiso Perhaps the most important recent finding was a large survival difference between three different centres im the USA where different approaches to treatment were followed..$^{10}$ Certainly the way in which medical care given seems to have a large influence on survival. The patients themselves know this and theirs are among the loudest voices arguing for special facilities.

There are, of course, several counterargument $\overrightarrow{\vec{\rho}}$ Patients in rural districts might have to travel long distances to their nearest centre, which is at be inconvenient and at worst dangerous in the event of an emergency. Perhaps only the well off would travel to special centres, leaving the poorer patients with inferior facilities, especially as specialist units migh reduce the experience gained locally. Against these. arguments are the difficulties of establishing a trukg experienced multidisciplinary team (physiotherapist: dietitians, social workers, etc) and of gaining experience in special treatments (bronchial artery embolisation, home intravenous therapy, trans plantation, etc) with only a few patients. A further important consideration is the high costs of care of patients with cystic fibrosis. Special funding and facilities will be achieved only by dedicated regiona units.

Perhaps the best solution will be to develop network of regional units to coordinate care, fight for resources, arrange research, provide highly specialise $\$$ services, and audit overall results. The detailed provi ision of day to day medical care can then be decided bo the thoracic physicians within the region and wit depend on local conditions. Often some form of shared care may prove ideal. 


\section{CONCLUSIONS}

1 The number of adults with cystic fibrosis in Britain will continue to rise for at least 15 years.

2 The number of children with cystic fibrosis will remain stable until population screening for the carrier state is introduced. Although this should, in theory, be possible quite soon long delays may be expected.

3 The prognosis for cystic fibrosis is continuing to improve and there are good prospects for new treatments providing further improvement.

4 The role of cystic fibrosis centres continues to be debated. The establishment of a network of regional units is recommended.

\section{DM GEDDES \\ Brompton Hospital \\ London}

\section{References}

1 Wainwright BJ, Scambler PJ, Schmidtke J, et al. Localisation of cystic fibrosis locus to human chromosome 7cen-q22. Nature 1985;318:384-5.

2 Knowles M, Gatzy JT, Boucher R. Increased bioelectric potential difference across respiratory epithelia in cystic fibrosis. N Engl J Med 1981;305:1489-94.
3 Frizzel RA, Retchkemmer G, Shoemaker RL. Altered regulation of airway epithelial cell chloride channels in cystic fibrosis. Science 1965;253:558-60.

4 Pederson PJ, Larsen EH, Brandt NJ. Restitution of chloride permeability in cystic fibrosis. Med Sci Res 1987;15:151-2.

5 Kohler D, Ernst APP, Schmitz-Schumann M, et al. Inhalation of amiloride improves the mucociliary and the cough clearance in patients with cystic fibrosis. Eur $J$ Respir Dis 1986;69(suppl 146):319-26.

6 Scott J, Higgenbotham T, Hutter J. Heart lung transplantation for cystic fibrosis. Lancet 1988;ii:192-4.

7 Phelan P, Hay E. Cystic fibrosis mortality in England and Wales and in Victoria, Australia, 1976-80. Arch Dis Child 1984;56:711-3.

8 Nielsen OH, Schiotz PO. Cystic fibrosis in Denmark in the period 1945-81. Evaluation of centralised treatment. Acta Paediatr Scand 1982;30(suppl):107-19.

9 Corey M, McLaughlin FJ, Williams M, Levison H. A comparison of survival, growth and pulmonary function in patients with cystic fibrosis in Boston and Toronto. J Clin Epidemiol 1988;41:583-91.

10 Wood RE, Piazza F. Survival in cystic fibrosis: correlation with treatment in three cystic fibrosis centres. In: Proceedings of 10th International Cystic Fibrosis Congress. Amsterdam: Excerpta Medica, 1988:79-80. (Asia Pacific Congress Series, 74.) 